\title{
The Psychology Of Phenomenological Structuralism
}

\author{
Paul Mocombe C* \\ West Virginia State University, The Mocombeian Foundation, Inc., Lauderhill, Florida, USA
}

*Corresponding author: Paul Mocombe C, West Virginia State University, The Mocombeian Foundation, Inc., Lauderhill, Florida, USA.
Received Date: January 22, 2021

Published Date: February 04, 2021

\section{Introduction}

This work highlights the psychology behind Paul C. Mocombe's theory of phenomenological structuralism. The author posits a cognitive developmental psychology that is tied to the theory's emergent logico-metaphysical materialist account regarding the formation, constitution, and perpetuation of the multiverse, consciousness, society, and the individual.

Paul C. Mocombe's structurationist theory of phenomenological structuralism, building on and synthesizing a form of M-theory with, mathematical elements of univon multiverse hypothesis, the quantum computation of ORCH-OR theory, Black Hole Big Bang Theory (BHBBT), structurationism, and the multiverse ideas of Haitian ontology/epistemology and quantum mechanics abductively posits that spacetime is fundamental; and consciousness is an emergent fifth force of nature, a field of consciousness (the consciousness field-CF) composed of an emergent quantum material substance/energy, psychion, the phenomenal property, qualia or informational content, of which is recycled/replicated/ entangled/superimposed throughout the multiverse and becomes embodied via the microtubules of neurons of brains and aggregate matter of multiple worlds to constitute mind. Mind (composed of the personal and collective unconscious, and the sense-experience of the emerging ego held together by the brain's electromagnetic field generated by the periodic discharge of neurons), in turn, is manifested in simultaneous, entangled, superimposed, and interconnecting material resource frameworks, multiple worlds, as praxis or practical consciousness of organic life, the content of which in-turn becomes the phenomenal properties, qualia, of material (subatomic particle energy, psychion) consciousness that is recycled/replicated/entangled/superimposed via the consciousness field throughout the multiverses upon matter disaggregation. In other words, existence precedes essence; but essence is emergent and eternal, and comes to constitute a fifth force of nature, a field of consciousness for Being production (the consciousness field), through the phenomenal properties, qualia (personal and collective unconscious), of neuronal subatomic particles, psychion, which are recycled/replicated/superimposed/ entangled throughout the multiverse and give human actors their initial (essential) practical consciousness that they organize and reproduce in replicated, entangled, and superimposed material resource frameworks. On this physics Mocombe builds his systemic philosophy, sociology, and psychology called, phenomenological structuralism. This work highlights the (cognitive) developmental psychology within Mocombe's theory of phenomenological structuralism.

\section{Background of the Problem}

From Freud to Erickson, Vygotsky, and Kholberg developmental psychologists attempt to describe, explain, and highlight how cognition, affect, and practical activities change or develop throughout a person's lifespan in order to optimize development and assist them in their practical situations. For the most part, the field focuses on the dialectical relationship between normative development, which highlight objective patterns of change and development; and idiographic development, which explores individual variations in patterns of development. The problem in 
the field to date is that developmental psychologists do a better job describing development as opposed to explaining how the changes they have observed in relation to normative processes and individual variations occur. In this work, I describe and explain how human psychological development and individuation unfolds within Paul C. Mocombe's theory of phenomenological structuralism.

Within Mocombe's theory of phenomenological structuralism the psychological assumptions are that human psychological development emerges from consciousness, which is an emergent fifth force of nature, a field of consciousness or consciousness field. Consciousness is an emergent fifth force of nature, a field of consciousness or the consciousness field, composed of an emergent quantum material substance/energy, psychion, the phenomenal property, qualia or informational content, of which is recycled/ replicated/entangled/superimposed throughout the multiverse and becomes embodied via the microtubules of neurons of brains and multiple worlds to constitute mind. Mind, composed of the personal and collective unconscious, and the emerging senseexperiences of the ego, qualia, held together or given uniformity and integrated as an I via the electromagnetic field of the brain is manifested in simultaneous, entangled, superimposed, and interconnecting material resource frameworks, multiple worlds, as praxis or practical consciousness of organic life, the content of which in-turn becomes the phenomenal properties, qualia, of material (subatomic particle energy, psychion) consciousness that is recycled/replicated/entangled/superimposed throughout the multiverses upon matter disaggregation. In other words, existence precedes essence; but essence is emergent and eternal, and comes to constitute a fifth force of nature, a field of consciousness for Being production, through the phenomenal properties, qualia (personal and collective unconscious sense experiences of past, present, and future existences), of neuronal subatomic particles, psychion, which are recycled/replicated/superimposed/entangled throughout the multiverse and give human actors their initial (essential and unconscious) practical consciousness that they organize and reproduce in replicated, entangled, and superimposed material resource frameworks.

The brain is a receiver of consciousness from an emergent consciousness field of the multiverse (Figure 1). This consciousness field theory, CFT, differs from [1]. conscious electromagnetic (EM) information (CEMI) field theory, which posits "that the seat of consciousness is simply the brain's EM field" (pg. 5), in that for me, the EM field of the brain is not the seat of consciousness; instead, it (the brain's EM field) serves more like a glue, which holds and integrates consciousness, which emerges from its on field, together. In other words, consciousness emerges out of a field composed of subatomic particles, psychions, which have phenomenal properties (qualia) and become embodied in the neurons of brains that constitute an electromagnetic field during their firing that holds the psychions together as an individuated consciousness in order to experience objective reality. McFadden's attempt to hold on to dualism by substituting spirit in the matter/spirit argument with the EM field of the brain is tautological. That is holding on to energy and matter to give a dualist account of consciousness is not a dualist account; instead, it is an incomplete materialist account. My consciousness field theory (CFT) completes McFadden's materialist account regarding the nature and origins of consciousness by arguing for a physics that views consciousness as an emergent fifth force of nature with its own field.

On this physics, Mocombe builds his systemic philosophy, sociology, and psychology called phenomenological structuralism by tying the emergence of the field of consciousness, the consciousness field, composed of psychions to human sociological and psychological development and experiences, which constitute the phenomenal properties (qualia) of the psychions, which form the tripartite structure (ego, personal and collective unconscious) of the emerging human mind manifested as their practical activities. Psychologically speaking, in other words, the field of consciousness or consciousness field is the basis for psychological development. The field is an emergent fifth force of nature composed of the psychion, which is the energy substance that constitutes and transmits the ego essence of an individual person to the microtubules of neurons of brains (Figure 1). The ego essence, psychion, is composed of all of the personal and collective sense experiences (personal and collective unconscious of the ego), the phenomenal properties or qualia, of the individual person, which becomes embodied in the microtubules of neurons in the brain as a result of matter aggregation across multiple simultaneous existing past/present/future worlds/universes. The structure of the mind, in the end, is composed of the ego and the personal and collective unconscious, which becomes embodied, as the qualia of psychions, via the microtubules of neurons of the aggregated brain and its EM field across replicated simultaneous past/present/future worlds of the multiverse. The EM field's "source is the electrical dipoles within the neuronal membranes caused by the motion of ions in and out of those membranes during action potentials and synaptic potentials. The periodic discharge of neurons-firing or action potentials- generates EMF waves that propagate out of the neuron and into the surrounding inter-neuronal spaces where they overlap and combine to generate the brain's global EM field that is routinely measured by brain scanning techniques such as electroencephalography (EEG) and magnetoencephalography (MEG)" (McFadden, 2020, pg. 5). The EM field integrates and holds together, like a glue, the ego essence, individuated consciousness of being, their psychion, which emerges out of its own (emergent) force, the consciousness field. The ego, in other words, is the (material) essence, psychion, of the individual being. It is a composite of their past/present/future experiences, which emerge as the personal and collective unconscious, i.e., qualia, of the ego. The latter two 
as such are the past/present/future biological and sociological sense experiences of the ego over all of its lived experiences across the multiverse. Following matter disaggregation, the psychion, either collapses unto other versions of itself still in existence in the multiverse or returns to the consciousness field. The individual, doing embodiment, only becomes aware of itself as an ego with personal and collective tastes that individuates them from other objects and persons when they encounter conflict, throughout their lifespan, in becoming and being-in-worlds constituted via five (sociological) systems, i.e., mode of production, language, ideology, ideological apparatuses, and communicative discourse.

The individual being, whose mechanical brain and electromagnetic field, is initially constituted as superimposed, entangled, recycled, and embodied subatomic particles, psychion, of multiple worlds of the multiverse, which have their own predetermined form of understanding and cognition, phenomenal properties, qualia, based on previous or simultaneous senseexperiences as aggregated matter (this is akin to what the Greek philosopher Plato refers to when he posits knowledge as recollection of the Soul; and Nietzsche's idea of eternal recurrence). Again, the individual's actions are not necessarily determined by the embodiment and drives (qualia or phenomenal properties) of these recycled (replicated)/entangled/superimposed subatomic particles in the neurons of the brain. It is conflict and an individual's stance, ready-to-hand, unready-to-hand, and present-at-hand, when the subatomic particles become aggregated matter or embodied, which determines whether are not they become aware, present-at-hand, of the subatomic particle drives and choose to recursively reorganize and reproduce the content of the drives as their practical consciousness.

This desire to reproduce the (essence) cognition and understanding of the (phenomenal properties/qualia) drives of the recycled/replicated/entangled/superimposed subatomic particles, however, may be limited by the structuring structure (chemical, biological, and physiological drives) of the aggregated body and brain of the individual subject. That is to say, the second origins and basis of an individual's actions are the structuring drives and desires, for food, clothing, shelter, social interaction, and sex, of the aggregated body and brain, which the subatomic particles constitute and embody. In other words, the aggregated body and brain is preprogrammed with its own (chemical, biological, and physiological) forms of sensibility, understanding, and cognition, structuring structure, by which it experiences being-in-a-world as aggregated embodied subatomic particles. These bodily forms of sensibility, understanding, and cognition, such as the drive and desire for food, clothing, shelter, social interaction, linguistic communication, and sex, are tied to the material embodiment and survival of the embodied individual actor, and may or may not supersede or conflict with the desire and drive of an individual to recursively (re) organize and reproduce the structuring structure of the superimposed, entangled, and recycled (phenomenal properties of) subatomic particles. If these two initial (unconscious) structuring structures are in conflict, the individual moves from the ready-to-hand to the unready-to-hand stance or analytics where they may begin to reflect upon and question their being-in-theworld prior to acting. Hence just as in the case of the structuring structure of the subatomic particles it is an individual being's analytics vis-à-vis the drives of its body and brain in relation to the impulses/drives of the subatomic particles, which determines whether or not they become driven by the desire to solely fulfill the material needs of their body and brain at the expense of the drives/ desires of the subatomic particles or the social class language game of the material resource framework they find their existence unfolding in.

The social class language game, and its differentiating effects, an individual find their existence unfolding in is the third structuring structure, which attempts to determine the actions of individual beings as they experience being-in-a-world as embodied subatomic particles. The aggregated individual finds themselves objectified and unfolding (Being) within a material resource framework controlled by the actions of other bodies, which presuppose their existence, via the actions of their bodies (practical consciousness), language, communicative discourse, ideology, and ideological apparatuses stemming from how they satisfy the desires of their bodies and subatomic particle drives (means and mode of production). What is aggregated and reified as a social class language game by those in power positions via and within its mode of production, language, ideology, ideological apparatuses, and communicative discourse attempts to interpellate and subjectify other beings to its interpretive frame of satisfying their bodily needs, fulfilling the impulses of their subatomic particles, and organizing a material resource framework at the expense of all others, and becomes a third form of structuring individual action based on the mode of production and how it differentiates individual actors.

That is to say, an individual's interpellation, subjectification, and differentiation within the social class language game that presupposes their being-in-a-world attempts to determine their actions or practical consciousness via the reified language, ideology, etc., of the social class language game, the meaning of which can be deferred via the communicative discourse of the individual actors allowing them to form social groups or heterogeneous communities tied to the dominant social order because of their control of the materials of the material resource framework. Hence, the deferment of meaning in ego-centered communicative discourse of the language and ideology of a social class language game is the final means of determining an individual's action or practical consciousness outside of, and in relation to, its stance, i.e., analytics, vis-à-vis the drives of subatomic particles, drives 
and desires (anatomy and physiology) of the body and brain, and structural reproduction and differentiation.

The interaction of all four elements or structuring processes in relation to the (mental) stance of the transcendental ego of the individual actor is the basis for human action, praxis/practical consciousness, and cognition/mind in a world. However, in the end, consequently, the majority of practical consciousness will be a product of an individual actor's embodiment and the structural reproduction and differentiation of a social class language game given 1) the determinant nature of embodiment, (anatomical and physiological) form of understanding and sensibility of the body and brain amidst, paradoxically, the indeterminacy of impulses of embodied subatomic particles and the neuronal processes involved in ego-centered communicative discourse; and 2) the consolidation of power of those who control the material resource framework wherein a society, the social class language game, is ensconced and the threat that power (consolidated and constituted via the actions of bodies, mode of production, language, ideology, ideological apparatuses, and communicative discourse) poses to the ontological security of an aggregated individual actor who chooses (or not) either ready-to-hand or present-at-hand to recursively reorganize and reproduce the ideals of the society as their practical consciousness. Lastly, the entire lived experiences (across the multiverses) of the individual being is recorded as the phenomenal properties, qualia, essence, of the psychions that constitute the field of consciousness, which is an emerging fifth force of nature.

\section{Theory and Methods}

Against philosophical dualism and idealism [2-4]. philosophy and structurationist sociology, phenomenological structuralism, which attempts to resolve the structure/agency problematic of the social sciences, is a logico-metaphysical materialist philosophy, which posits that we live in a material multiverse composed of brute facts, which human consciousness reifies as ideas, concepts, and theories via language and the abstractions of space/time geometry and mathematics (Mocombeian nominalism) in order to experience, understand, and be in the world for our survival: hence the emergence of religion, science, and the scientific process. For [1], quantum superposition, entanglement, wave-function realism, and evidence in Haitian Vodou of psychic phenomena and spirit possession, which represent ancestors from a parallel world, Vilokan, of the earth's of which we ought to pattern our behaviors and structures, are grounding proofs for the acceptance of the multiple worlds hypothesis of quantum mechanics. Within the latter hypothesis, the understanding is that "each possibility in a superposition evolves to form its own universe, resulting in an infinite multitude of [(replicated)] coexisting 'parallel' worlds. The stream of consciousness of the observer is supposed somehow to 'split', so that there is one in each of the worlds-at least in those worlds for which the observer remains alive and conscious. Each instance of the observer's consciousness experiences a separate independent world and is not directly aware of any of the other worlds" [5]. It is within this multiple world hypothesis, physics, that Mocombe constitutes his understanding of the emergence of the material multiverse, the notion of consciousness in each of the universes according to his theory of phenomenological structuralism, and human psychological development.

For Mocombe, consciousness, like the material multiverse, is emergent; an emergent fifth force of nature, a field of consciousness or consciousness field composed of a quantum material substance/ energy, psychion (which constitutes a "field of consciousness), the phenomenal properties, qualia, of which are recycled/ replicated/entangled/superimposed throughout the multiverse and becomes embodied via the microtubules of neurons of brains and their electromagnetic field. It (consciousness), held together and integrated by the brain's electromagnetic field, is manifested in simultaneous, entangled, superimposed, and interconnecting material resource frameworks as mind or embodied praxis or practical consciousness, the sense-experiences in-turn become the phenomenal properties (informational content), qualia, of material (subatomic particle energy, psychion) consciousness that is recycled/entangled/superimposed throughout the multiverses following matter disaggregation. In other words, existence precedes essence; but essence is emergent and eternal, and comes to constitute a fifth force of nature, a field of consciousness or consciousness field for Being production, through the phenomenal properties, qualia, of neuronal subatomic particles, psychions, which are recycled/replicated/superimposed/entangled throughout the multiverse and give human actors their initial (essential) practical consciousness embodied and recursively organized and reproduced as the personal and collective unconscious praxis of an individuated ego-essence held together and integrated by the brains EM field.

Be that as it may, the essentialist assumptions inherent in this logico-metaphysical materialist view are that:

- Thought precedes language as a result of qualia, informational content or phenomenal properties (personal and collective unconscious), of psychions (ego-essence), which become embodied as a result of matter aggregation.

- Languages of heterogeneous speech communities are emergent in the cerebral cortex of the embodied brain and attempt to capture the nature of reality as such through syntax or generative grammar and the language games of those who control the resources of a material resource framework.

- $\quad$ The signs (signifier and signified) of the language games of those who control the resources of a material resource framework are arbitrary. 
- Two linguistic systems emerge and dominate heterogeneous speech communities, the ordinary language of a speech community and the language of science/religion, which (via the-present-at-hand stance, observation, experimentation, and abstraction or idealization) attempts to capture the nature of reality as such (the idealization of brute facts) by which members of speech communities must recursively reorganize and reproduce their being-in-the-world through their generative grammar and speech acts.

- $\quad$ Ordinary languages are conventional and rule governed based on the rules of the social class language game (personal and collective unconscious) of those who control the resources of a material resource framework and not necessarily the language of science/religion, which is also rule-governed but in relation to its abstractions about the nature of reality as such.

Hence in phenomenological structuralism the reading is that consciousness is the by-product or evolution of subatomic particles, psychions, unfolding, as qualia (subjective and collective informational content), with increasing levels of abstraction within an evolutionary material resource framework enframed by the mode of production, language, ideology, ideological apparatuses, and communicative discourse, i.e., social class language game, of bodies (who control the material resource framework) recursively reorganizing and reproducing the language and ideals (conventions) of the latter factors as their practical consciousness or activity. Within this perspective, thought precedes language as a result of conflict and the phenomenal properties, qualia, of embodied subatomic particles, which direct action in an emergent material world via impulses or drives of past/present/ future sense-experiences (personal and collective unconscious). (Ordinary) language is an emergent system generated from an innate structure of the embodied brain in order so that we can be in the world, communicate, and do things with the other things and beings we experience the world with for our survival. Thus, in phenomenological structuralism the understanding is that the structure of reality determines language (via its generative grammar) and how we ought to live and do things in the world for our survival amidst the internal thought processes (essences) of phenomenal properties, qualia, of psychions of individuals. However, the (ordinary) language, and its usage, i.e., social class language game (personal and collective unconscious), of those who control the material resource frameworks of the world conceals that relationship (the relationship between the individual and the structure of reality as such) via their mode of production, language, ideologies, ideological apparatuses, and communicative discourse (ordinary language), which is evolutionary. In other words, like the Wittgensteinian position of the Tractatus, Mocombe's theory of phenomenological structuralism assumes that there is a uniform (grammatical/syntactical) structure to language determined by the logical-empirical structure of (quantum and physical) reality. The grammatical structure of linguistic utterances and sentences attempt to capture the subjects, objects, and states of affairs of that reality and how we ought to live in it and among them for our survival. In being-in-the-world with others, this logicalgrammatical structure, however, is concealed by the evolution and developmental knowledge, and its usage (practical activity), of those who control the material resource framework of the world via the stage of development of their language, ideology, ideological apparatuses, social relations of production, and communicative discourse (ordinary language/collective unconscious). Be that as it may, the latter comes to constitute an evolutionary social class language whose linguistic systemicity and usage comes to determine our conception of reality, and the classes, categories, and forms of life we belong to and interact in and with, which depending on its stage of development and relation to the True nature of reality as such as idealized by science/religion, is either accepted or constantly deferred by those individuals in its speech community who are marginalized or not represented in its evolutionarily developed linguistic systemicity. The latter process under the guise "language game," language as a tool, is what Wittgenstein captures in his second treatise on language as developed in the Philosophical Investigations.

That is, the classes and categories created by the dominant social class language game of a material resource framework, in their efforts to capture the logical-grammatical structure of reality and how we ought to live within it, constitute reified classes, categories, and forms of life, "language games," whose meanings and praxes as defined by the dominant social class language game are either accepted or deferred by those individuals classified in them (based on their 1) qualia, 2) drives of the body, or 3) their abilities to defer meaning in ego-centered communicative discourse). The latter may in-turn seek to reify their form of life that they are marginalized for, or categorized in, as a distinct alternative practical consciousness or heterogeneous community to that of the dominant order thereby undermining the attempted universality of the logical-grammatical structure of the dominant order for notions of diversity, intersectionality, etc.

So in Mocombe's theory of phenomenological structuralism, Ludwig Wittgenstein's two theories of language and meaning must be read as one philosophy as opposed to two, one supported by analytical philosophy and the other by postmodernism/poststructuralism. We have a plethora of (ordinary) language games (classes, forms of life, and categories), heterogeneous speech communities, in the world, which structures our language, because of the ability to defer meaning in ego-centered communicative discourse and the developmental stage of the human mind and body vis-à-vis the actual structure of reality. The language of science, like its predecessor religion, attempts (via observation, 
experimentation, and idealization) to capture the "True" logicalempirical structure of (quantum and physical) reality, and how we ought to live within it, amidst the (ordinary) utterances and practical consciousnesses of the masses given their abilities to defer meaning in ego-centered communicative discourse and the classes, categories, and forms of life they are classed in/with by the dominant social class language game as they attempt to be in the world via their (ordinary) language, which following matter disaggregation the content of which becomes the personal and collective unconscious of the ego.

To formulate the basic premise of this physic and metaphysic, I adopt from the "membrane theory" model of Lisa Randall and Raman Sundrum (1999) the assertion, in keeping with the logic of Haitian Vodou, that there might be an additional dimension on the cosmological scale, the scale described by general relativity, which gives rise to four dimensional multiverses within it. That is to say, our universe is embedded in a vastly bigger five-dimensional space (the four-dimensional space of relativity, plus a fifth dimension for the subatomic forces including consciousness), a kind of super-universe. Within this super-space, our universe is just one of a whole array of co-existing universes (Haitian Vodou only accounts for our universe and its parallel), each a separate fourdimensional bubble within a wider arena of five-dimensional space where consciousness (a subatomic force) is recycled/replicated/ entangled/superimposed between the phenomenal properties/ informational contents of the species of the five-dimensional superspace, i.e., superverses, and their four-dimensional multiverses (Figure 2).

The origins of consciousness and the multiverse within this phenomenal structural paradigm is material and emergent, and not the product of a supreme creator or god. For this position, I build on the mathematics of [6]. in his "univon multiverse hypothesis." Unlike Gauthier, who holds on to God or a supreme creator to account for the origins and nature of consciousness within the multiverse, I do not. According to [6] model, identical univon quantum particles, produced from a univon quantum field, created not only our universe but also many other identically finetuned universes in a multiverse. The univon, also called a cosmic quantum, is composed of a helically circulating superluminal primordial information quantum (sprinq). [(The univon is the quantum particle of a conscious cosmic quantum field having both physical and mental potentialities. Quantum fields may be composed of cosmic ectoplasm or mind-stuff, which according to yoga philosophy is a subtle vibrational substance formed from consciousness by a cosmic creative power, that takes the form of objects within a cosmic mind)].

The physical [(and mind-stuff)] constants carried in the information content of each univon's sprinq are exactly the same in all univons and in all sprinqs, though sprinqs express different fundamental particle attributes in different environments. The univon is radioactive. The decay of a univon into less energetic products is the starting point $(\mathrm{t}=0)$ of its created universe. The univon's sprinq rapidly multiplies itself into different quantum fields and particles, leading very quickly to the early universe's exponentially rapid inflationary period and then to the Big Bang, which produces abundant relic dark matter particles of the universe as well as the less abundant ordinary matter. Univons made many other [(entangling)] equally fine-tuned universes with identical fundamental forces and constants.... (pgs. 1-3).

In my metaphysical materialistic model, which differs in language and the need for a "cosmic mind," the "univon" is the cosmological scale described by Einstein constituted by the forces, constants, particles, etc., sprinqs in Gauthier's hypothesis and phenomenal properties or qualia in my model, of the multiverses, with gravity and the psychionic force of consciousness emergent forces following matter aggregation, evolution, and disaggregation, which give rise to inflation, big bangs, and additional (entangled) universes with similar (replicated) informational (physical and mental) content. Hence, the mathematics for both models are the same as seen in Figures 1 and 2, which is adopted from [6].

I tie this physical model to Black Hole Big Bang Theory (BHBBT)-the understanding "that matter from a mother universe collapses into a black hole. The singularity of this black hole is at a single point in space with respect to anyone in the mother universe. But, because of the reversal of time and space for anyone inside the daughter universe, that point in space $r=0$ become their initial point in time, $\mathrm{t}=0$. Hence, what was a singularity in space is now a singularity in time, just like the Big Bang. This means that any matter falling in from the mother universe will disappear from that universe and emerge at the initial $t=0$ point of the daughter universe thoroughly scrambled. Not only that, but what emerges at the Big Bang is not just the matter that was there at the black hole's formation but all matter that ever fell into it." [7]-and Mocombe's structuration theory, phenomenological structuralism, to explain the emergence and constitution of the multiverses, consciousness, minds, and society in them (Figure 3,4).

\section{Structurationism and Phenomenological Structuralism}

To the aforementioned physical and metaphysical processes (the brute fact that we are a product of a multiverse that has always existed, which is entangled, superimposed, and replicated via black holes), I add the psychology and sociology of Mocombeian structuration theory to account for the emergence of human action and its relation to consciousness in the determinism of the multiverses and the constitution of societies. Structurationist sociology synthesizes structure and agency via the concept of 
praxis or practical consciousness; accounting for human agency or practical consciousness via the actions associated with (societal) structural reproduction and differentiation within a particular material resource framework [8-9]. This latter factor, however, does not account for the moments or movements, which escape from the compound of socially constructed identifications, which for Mocombe is epiphenomenal. Building on structurationist sociology in relation to the physics and metaphysics of phenomenological structuralism, Mocombe argues that the "moments, or movements, which escape from the compound of socially constructed identifications" are the product of an individual actors' (mental) stance/analytics (Martin Heidegger's term) vis-à-vis three types of structures/systems of signification amidst the practical consciousness associated with societal structural reproduction and differentiation (the social system), which is a tertiary process: 1 ) the (chemical, biological, and physiological) drives (forms of sensibility and understanding) of the body and brain (the biological system), 2) impulses or phenomenal properties of residual past/present/future consciousnesses or recycled/replicated/entangled/superimposed subatomic/chemical particles, psychions, encapsulated in and as the neuronal energies and qualia of the brain via microtubules (the physical system), 3) and actions or practical consciousnesses resulting from the deferment of meaning in ego-centered linguistic and symbolic communicative discourse (the linguistic system). Our ability to perform the latter, defer meaning in ego-centered communicative discourse, is what gives us as a species the illusion of choice and free-will amidst the aforementioned determining structures the second of which is tied to our connection to the (physical) multiverse and its constitution.

Generally speaking, consciousnesses, actions (practical consciousness), learning, and development within Mocombe's phenomenological structural ontology are the product of the embodiment of the phenomenal properties, qualia, of recycled/ replicated/entangled/superimposed subatomic neuronal energies/ chemicals, psychion, of the multiverse objectified in the space-time of multiverses via the aggregated body and the microtubules of the neurons of the brain and its EM field. Once objectified and embodied the phenomenal properties, qualia, of the neuronal energies/ chemicals, psychion, encounter the space-time of physical worlds via a transcendental subject of consciousnesses (the aggregation of a universal-self, the ego-essence with phenomenal properties, replicated, superimposed, and entangled across the multiple worlds of the multiverse) held together and integrated by the brain's EM field and the drives and sensibilities of the aggregated body and brain in reified structures of signification, language, ideology, ideological apparatuses, and communicative discourse defined and determined by other beings that control the resources (economics), and modes of distributing them, of the material world required for physical survival in space-time.
The Heideggerian (mental) stances/analytics, "ready-to-hand," "unready-to-hand," and "present-at-hand," which emerge as a result of conflict between the embodied transcendental ego (qualia) vis-à-vis its different (structuring) systems, 1) the sensibilities and (chemical, biological, and physiological) drives of the body and brain, 2) drives/impulses of embodied residual memories or phenomenal properties of past/present/future recycled/ entangled/superimposed subatomic/chemical particles, 3) the actions produced via the body in relation to the indeterminacy/ deferment of meaning of linguistic and symbolic signifiers as they appear to individuated consciousnesses in ego-centered communicative discourse, 4) and the dialectical and differentiating effects, i.e., structural reproduction and differentiation, of the structures of signification, social class language game, of those who control the economic materials (and their distribution, i.e., mode of production) of a world are the origins of practical consciousnesses. All four types of actions, the drives and sensibilities of the body and brain, drives or phenomenal properties of embodied recycled/replicated/entangled/superimposed past/present/ future consciousnesses, structural reproduction/differentiation stemming from the mode of production, and deferential actions arising from the deferment of meaning in ego-centered communicative discourse via the present-at-hand stance/analytic, exist in the material world with the social class language game, i.e., the physical, mental, emotional, ideological, etc. 5) powers of those who control the material resource framework as the causative agent for individual behaviors. In other words, our (mental) stances in consciousness vis-à-vis the conflict (or lack thereof) between the (chemical, biological, and physiological) drives and sensibilities of the body and brain, (societal) structural reproduction and differentiation, drives (personal and collective unconscious) of embodied past/present/future consciousnesses of recycled/entangled/superimposed subatomic/chemical particles, and deferential actions arising as a result of the deferment of meaning in ego-centered communicative discourse determines the practical consciousness we want to recursively reorganize and reproduce in the material world. The power, power positions, and power relations of those who control (via the mode of production, language, ideology, ideological apparatuses, and communicative discourse) the resources (and their distribution, i.e., mode of production) of a material resource framework, and the threat it poses to the ontological security of an actor, in the end determines what actions and identities are allowed to organize and reproduce in the material world without the individual actor/agent facing marginalization or death.

It is Being's (mental) stance/analytic, "ready-to-hand," "unready-to-hand," and "present-at-hand," in consciousness vis-àvis the conflict, or lack thereof, between the (chemical, biological, and physiological) drives and sensibilities of the aggregated body 
and brain, drives/impulses (phenomenal properties) of residual past/present/future consciousnesses of recycled/replicated/ entangled/superimposed subatomic particles, alternative practices which arise as a result of phenomenological meditation and deferment of meaning, along with the differentiating logic or class divisions of the social relations of production, which produces the variability of actions and practices in cultures, social structures, or social systems and gives us the illusion of free-will. All four types of actions are always present and manifested in a social structure to some degree contingent upon the will and desires of the economic social class, power elites, which controls the material resource framework through its body (practical consciousness), language/ symbols, ideology, ideological apparatuses, and social relations of production. They choose, amidst the class division of the social relations of production, what other meaning constitutions and practices manifest themselves in the material world without facing alienation, marginalization, domination, or death.

Hence, we never experience the things-in-themselves of the world culturally and historically in consciousness. We experience them structurally or relationally, the structure of the conjuncture of the mode of production, its language, ideology, ideological apparatuses, etc., and our (mental) stances/analytics, ready-tohand, unready-to-hand, present-at-hand, vis-à-vis these things as they appear to and in consciousness determine our practical consciousness or behaviors.

We initially know, experience, and utilize the things of and in consciousness in the preontological ready-to-hand mode, which is structural and relational. That is, our bodies encounter, know, experience, and utilize the things of the world in consciousness, intersubjectively, via their representation as objects of knowledge, truth, usage, and experience enframed and defined in the relational logic and practices or language game (Wittgenstein's term) of the institutions or ideological apparatuses of the other beings-ofthe-material resource framework whose historicity comes before our own and gets reified in and as the actions of their bodies, language, ideology, ideological apparatuses, mode of production, and communicative discourse. This is the predefined phenomenal structural, i.e., ontological, world we and our bodies are thrown-in in coming to be-in-the-world. How an embodied-hermeneuticallystructured Being as such solipsistically view, experience, understand, act, and utilize the predefined objects of knowledge, truth, and experienced defined by others and their conditions of possibilities in consciousness in order to formulate their practical consciousness is albeit indeterminate. Martin Heidegger in Being in Time is accurate, however, in suggesting that three stances or modes of encounter (Analytic of Dasein), "presence-at-hand," "readiness-to-hand," and "un-readiness-to-hand," characterizes our views of the things of consciousness represented intersubjectively via bodies, language, ideology, and communicative discourse, and subsequently determine our practical consciousness or social agency. In "ready-to-hand," which is the preontological mode of human existence thrown in the world, we accept and use the things in consciousness with no conscious experience of them, i.e., without thinking about them or giving them any meaning or signification outside of their intended usage. Heidegger's example is that of using a hammer in hammering.

We use a hammer without thinking about it or giving it any other condition of possibility outside of its intended usage as defined by those whose historicity presupposes our own. In "present-at-hand," which, according to Heidegger, is the stance of science, we objectify the things of consciousness and attempt to determine and reify their meanings, usage, and conditions of possibilities as the nature of reality as such. Hence the hammer is intended for hammering by those who created it as a thing solely meant as such. The "unreadyto-hand" outlook is assumed when something goes wrong in our usage of a thing of consciousness as defined and determined by those who adopt a "present-at-hand" view. As in the case of the hammer, the unready-to-hand view is assumed when the hammer breaks and we must objectify it, by then assuming a present-athand position, and think about it in order to either reconstitute it as a hammer, or give it another condition of possibility. Any other condition of possibility that we give the hammer outside of its initial condition of possibility which presupposed our historicity becomes relational, defined in relation to any of its other conditions of possibilities it may have been given by others we exist in the world with who either ready-to-hand, unready-to-hand, or present-athand attempts to maintain the social class language game of power. In the ready-to-hand stance the latter unconsciously practices and attempts to reproduce the social class language game of power by discriminating against and marginalizing any other conditions of possibilities of their social class language as determined by those in ideological power positions [10-20].

They may move to the unready-to-hand stance in response to those who they encounter that attempts, present-at-hand, to alter the nature of the dominant social class language game they recursively reorganize and reproduce as outlined by those in power positions who are present-at-hand of the dominant social class language game. In either case, not all beings achieve the present-at-hand stance. The latter is the stance of science and ideologies, which are tautologies when they profess that their stances represent the nature of reality as such, and those in power positions, who choose, among a plethora of alternative presentat-hand social class language games, what alternative practical consciousnesses outside of their social class language game that are allowed to manifest in the material world. 
The Evolution of Consciousness, Individual Psychology, and Mind within Phenomenological Structuralism

Hence, as outlined above, phenomenological structuralism posits consciousness to be the by-product or evolution of subatomic particles, psychion, with phenomenal properties, qualia, embodied and unfolding (out of an emergent consciousness field) with increasing levels of abstraction within entangled, replicated, and superimposed material resource frameworks enframed by the mode of production, language, ideology, ideological apparatuses, and communicative discourse (i.e., social class language game) of bodies recursively reorganizing and reproducing the ideals of the latter factors as their practical consciousness. That is to say, the logical consequence regarding the evolution and constitution of the multiverses, and their contents, based on the assumptions of superposition, action-at-a-distance, wave-function realism, phenomenal properties, and panpsychism of quantum mechanics, for Mocombe, is similar to the intersecting worlds theory highlighted in Haitian Vodou, which parallels the physics, "membrane theory," of Lisa Randall and Raman Sundrum (1999). The proposal in keeping with the logic of Haitian Vodou and the "brane theory" of Randall and Sundrum is that there might be an additional dimension on the cosmological scale, the scale described by general relativity, which gives rise to four dimensional multiverses within it. That is to say, our universe is embedded in a vastly bigger five-dimensional space (the four-dimensional space of relativity, plus a fifth dimension for the subatomic forces including consciousness), a kind of superuniverse. Within this super-space, our universe is just one of a whole array of co-existing, entangled, and superimposed universes (Haitian Vodou only accounts for our universe and its parallel), each a separate four-dimensional bubble, which share the same informational contents via black holes (BHBBT), within a wider arena of five-dimensional space where consciousness (a subatomic force, i.e., psychion, and it's phenomenal properties, qualia) emerges and is recycled/replicated/entangled/superimposed between the five-dimensional super-space, i.e., superverses, and their multiverses.

For Mocombe the multiverses originated, from the superuniverses, either by fiat or quantum fluctuation. They are bosonic forces that were brought forth together with fermion counterparts. They are also the primeval pan-psychic fields, stemming from the superimposed and entangled super-verses, whose fermion can be called a psychion, a particle of consciousness or protoconsciousness. These have evolved together with the four forces of nature, electromagnetic force; gravity; the strong nuclear force; and weak nuclear force, in our universe, which in turn produced atoms, molecules, and aggregated life endowed (embodied) with the recycled/replicated/entangled/superimposed consciousness and phenomenal properties, qualia or informational content, of the primeval pan-psychic fields, psychion (the fifth force of nature), of the superverses and their multiverses. In other words, the superverses with entangled and superimposed (via black holes) multiverses share the same informational content. So, the hypothesis here is that one (original) superverse created a universe, and its informational content is entangled and superimposed on top of another superverse with the informational content of the previous universe emerging and replicating in it via black holes. Hence, what you have are layers of multiverses and superverses, superimposed and entangled, whose informational contents are shared or recycled and replicated via black holes, which organize and structure the multiverses similarly. As such, the basic idea for this Black Hole Big Bang Theory (BHBBT) is that quantum fluctuation and big bangs are constantly occurring and producing the same worlds, superimposed and entangled, ad infinitum. So, when physicists look out to the cosmic microwave background (CMB), they are looking at the remnant from an early stage of our universe, which came forth from its older version a layer above it, and so on ad infinitum (see Figure 3). Put more concretely, the physicists are in a superverse, of our universe, in our milky-way galaxy, looking out to the black hole of a milky-way galaxy from the superverse/multiverse above us.

Within these same worlds or multiverses, subatomic particles, via the Higgs boson particle, give/gave rise to carbon atoms, molecules and chemistry, which give/gave rise to DNA, biological organisms, neurons and nervous systems, which aggregate/aggregated into bodies and brains that give/gave rise to the embodiment of preexisting consciousness of the subatomic particles, bodies, and languages from entangled/superimposed multiverses. In human beings, the indeterminate behavior of superimposed, entangled, and replicated subatomic neuronal energies that produced the plethora of consciousnesses and languages in the neocortex of brains gave rise to ideologies, which in turn gave rise to ideological apparatuses and societies (sociology) under the social class language game or language, ideology, and ideological apparatuses of those who organize and control the material resources (and their distribution) required for physical (embodied) survival in a particular resource framework. In other words, existence precedes essence; but essence is emergent and eternal, and comes to constitute a fifth force of nature, a field of consciousness or consciousness field for Being production, through the phenomenal properties, qualia, of neuronal subatomic particles, psychions, which are recycled/replicated/superimposed/ entangled throughout the multiverse and give human actors their initial (essential) practical consciousness among the structuring structure of the drives of the biological body, a social structure or social class language game, and the ability to defer meaning in egocentered communicative discourse. 
So contrary to Karl Marx's materialism which posits human consciousness to be the product of material conditions, the logic here is a structural Marxist one in the Althusserian sense. That is, the aggregated, atomic, mature human being is a body and neuronal drives that never encounters the (ontological) material world directly. Instead, they encounter the (ideological) world via structures of signification, which structures the world or a particular part of it through the body, language, ideology, ideological apparatuses, and communicative discourse, i.e., social class language game, of those whose power, power positions, and power relations dictate how the resources of that framework are to be gathered, used, and distributed (means and mode of production).

Hence in the end, societal and subject constitution, mind organizing and reproducing consciousness as praxis, is a product of conflict and an individual's mental stance, i.e., analytics, vis-àvis three structures/systems of signification and the ability to defer meaning in ego-centered communicative discourse stemming from the social class language game (i.e., language, symbols, ideology, ideological apparatuses, and communicative discourse) of those who control the mode of production of a material resource framework. It is the ready-to-hand drives of the body and brain, ready-to-hand and present-at-hand manifestation of past/present/ future recycled residual consciousnesses/subatomic particles, the present-at-hand phenomenological meditation and deferment of meaning that occurs in embodied consciousness via language, ideology, and communicative discourse as reflected in diverse individual practices, within the ready-to-hand, unready-to-hand, and present-at-hand differentiating logic or class divisions of the social relations of production, which produces the variability of actions and practices in cultures, social structures, or social systems. All four types of actions, the (chemical, biological, and physiological) drives/impulses of the body and residual past consciousnesses of subatomic particles, structural reproduction/differentiation, and actions resulting from the deferment of meaning in ego-centered communicative discourse, are always present and manifested in a social structure (which is the reified ideology via ideological apparatuses, their social class language game, of those who control a material resource framework) to some degree contingent upon the will and desires of the economic social class that controls the material resource framework through the actions of their bodies (practical consciousness), language, symbols, ideology, ideological apparatuses, and social relations of production. They choose, amidst the class division of the social relations of production, "the structure of the conjuncture," (Marshall Sahlins's term) what other meaning constitutions and practices are allowed to manifest themselves without the Beings of that practice facing alienation, marginalization, domination, or death.

Hence psychological speaking, the individual being is initially constituted as superimposed, entangled, recycled, and embodied subatomic particles, psychion, of multiple worlds of the multiverse, which have their own predetermined form of understanding and cognition, phenomenal properties, qualia (personal and collective unconscious), based on previous or simultaneous experiences of multiword as aggregated matter (this is akin to what the Greek philosopher Plato refers to when he posits knowledge as recollection of the Soul; and Nietzsche's idea of eternal recurrence). The psychions, which have informational content, qualia, are embodied and integrated in the microtubules of neurons of brains and their electromagnetic field, which holds together and integrates consciousness as an ego-essence that initially drives practical consciousness/activity unconsciously (Figure 1). Again, the individual's actions are not necessarily determined by the embodiment and drives of these recycled (replicated)/entangled/ superimposed subatomic particles and their informational content (qualia, personal and collective unconscious). It is conflict and an individual's stance, ready-to-hand, unready-to-hand, and presentat-hand, when the subatomic particles become aggregated matter or embodied, and throughout their life-cycle, which determines whether are not they become aware, present-at-hand (third person perspective), of the subatomic particle drives and choose to recursively reorganize and reproduce the content of the drives as their practical consciousness [21-39].

This desire to reproduce the cognition and understanding of the (personal and collective unconscious) drives of the recycled/ replicated/entangled/superimposed subatomic particles, psychions, however, may be limited by the structuring structure of the aggregated body and brain of the individual subject. That is to say, the second origins and basis of an individual's actions are the structuring drives and desires, for food, clothing, shelter, social interaction, and sex, of the aggregated body and brain, which the subatomic particles constitute and embody. In other words, the aggregated body and brain is preprogrammed with its own (chemical, biological, and physiological) developing forms of sensibility, understanding, and cognition, structuring structure, by which it experiences being-in-a-world as aggregated embodied subatomic particles with phenomenal properties (personal and collective unconscious).

These bodily forms of sensibility, understanding, and cognition, such as the drive and desire for food, clothing, shelter, social interaction, linguistic communication, and sex, are tied to the material embodiment and survival of the embodied individual actor, and may or may not supersede or conflict with the desire and drive of an individual to recursively (re) organize and reproduce the structuring structure of the superimposed, entangled, and recycled (phenomenal properties, personal and collective unconscious, of) subatomic particles. If these two initial structuring structures are in conflict, anytime throughout the lifecycle, the individual moves from the ready-to-hand to the unready-to-hand stance or 
analytics where they may begin to reflect upon and question their being-in-the-world prior to acting. Hence just as in the case of the structuring structure of the subatomic particles it is an individual being's analytics vis-à-vis the drives of its body and brain in relation to the impulses/drives (personal and collective unconscious) of the subatomic particles, which determines whether or not they become driven by the desire to solely fulfill the material needs of their body and brain at the expense of the drives/desires of the subatomic particles or the social class language game of the material resource framework they find their existence unfolding in.

The social class language game (the institutionalized personal and collective unconscious of those who control a material resource framework), and its differentiating effects, an individual find their existence unfolding in is the third structuring structure, which attempts to determine the actions of individual beings as they experience being-in-the-world as embodied subatomic particles. The aggregated individual finds themselves objectified and unfolding (developing) within a material resource framework controlled by the actions of other bodies, which presuppose their existence, via the actions of their bodies (practical consciousness), language, communicative discourse, ideology, and ideological apparatuses stemming from how they satisfy the desires of their bodies and subatomic particle drives (means and mode of production). What is aggregated as a social class language game by those in power positions via and within its mode of production, language, ideology, ideological apparatuses, and communicative discourse attempts to interpellate and subjectify other beings to its interpretive frame of satisfying their bodily needs, fulfilling the impulses of their subatomic particles, and organizing a material resource framework at the expense of all others, and becomes a third form of structuring individual action based on the mode of production and how it differentiates individual actors.

That is to say, an individual's interpellation, subjectification, and differentiation within the social class language game that presupposes their being-in-a-world attempts to determine their actions or practical consciousness via the reified language, ideology, etc., of the social class language game, the meaning of which can be deferred via the communicative discourse of the individual actors allowing them to form social groups or heterogeneous communities tied to the dominant social order because of their control of the materials of the material resource framework. Hence, the deferment of meaning in ego-centered communicative discourse of the language and ideology of a social class language game is the final means of determining an individual's action or practical consciousness outside of, and in relation to, its stance, i.e., analytics, vis-à-vis the drives of subatomic particles, drives and desires (anatomy and physiology) of the body and brain, and structural reproduction and differentiation. The (mental) stance of the transcendental ego and the ability to defer meaning in ego- centered communicative discourse within a social class language game are what accounts for the feeling or illusion of free-will.

In other words, whereas the practical consciousness of the transcendental ego stemming from the impulses of embodied subatomic particles are indeterminant as with its neuronal processes involved with the constitution of meaning in ego-centered communicative discourse (Albeit physicists are in the process of exploring the nature, origins, and final states of subatomic particles, and neuroscientists are attempting to understand the role of neuronal activities in developing the transcendental ego and whether or not it continues to exist after death). The form of the understandings and sensibilities of the body and brain are determinant as with structural reproduction and differentiation of the mode of production, and therefore can be mapped out by neuroscientists, biologists, and sociologists to determine the nature, origins, and directions of societal constitution and an individual actor's practical consciousness unfolding/developing.

The interaction of all four elements or structuring processes in relation to the (mental) stance of the transcendental ego of the individual actor is the basis for human action, praxis/practical consciousness, and cognition/mind in a world. However, in the end, consequently, the majority of practical consciousness will be a product of an individual actor's embodiment and the structural reproduction and differentiation of a social class language game given 1) the determinant nature of embodiment, (anatomical and physiological) form of understanding and sensibility of the body and brain amidst, paradoxically, the indeterminacy of impulses of embodied subatomic particles and the neuronal processes involved in ego-centered communicative discourse; and 2) the consolidation of power of those who control the material resource framework wherein a society, the social class language game, is ensconced and the threat that power (consolidated and constituted via the actions of bodies, mode of production, language, ideology, ideological apparatuses, and communicative discourse) poses to the ontological security of an aggregated individual actor who chooses (or not) either ready-to-hand or present-at-hand to recursively reorganize and reproduce the ideals of the society as their practical consciousness. It should be mentioned that in response to this latter process, those in power positions who internalize the ideals of the social structure and recursively (re) organize and reproduce them as their practical consciousness are in the unready-to-hand stance when they encounter alternative forms of being-in-theworld within their social class language game. They dialectically attempt to reconcile the practical consciousness of their social class language game with the reified practical consciousness of those who have deferred their meanings for alternative forms of beingin-the-world within their social class language. They can either accept, marginalize, or seek to eradicate the deferred or decentered subject or their practices. 
Future research must 1) continue to search for evidence of multiverses and other forms of existence tied to our present world, which will be similarly constituted as our own universe, and 2) proofs for the existence of the field of consciousness or consciousness field and its force, psychion, in order to falsify or verify Mocombe's overall theory of phenomenological structuralism (Figures 1,2).
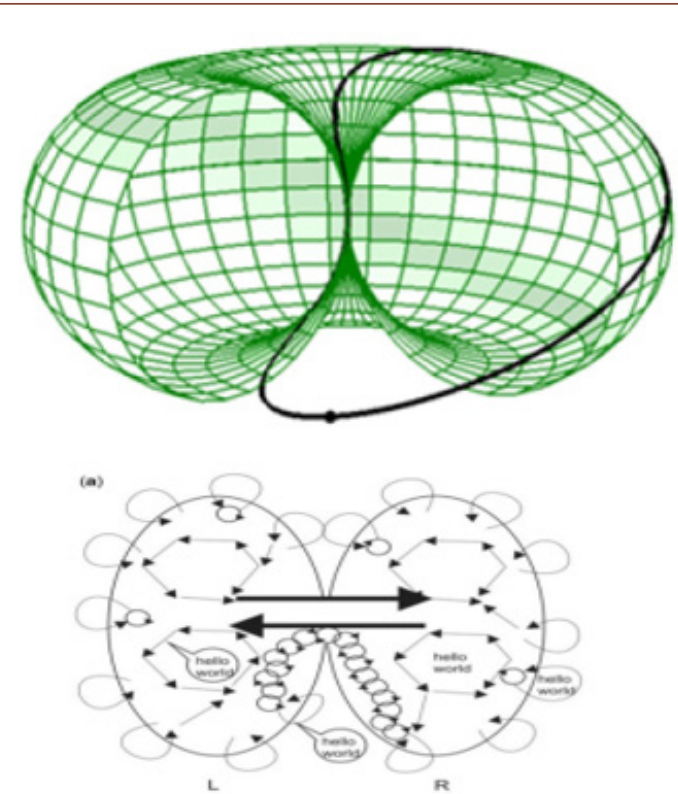

Figure 1: This figure represents how the psychions are embodied from the consciousness field (CF) in the microtubules of neurons of brains (figure a, adopted from McFadden, 2020, represents the human brain-left (L) and right (R) hemispheres—and its EM field, which holds together and integrates the qualia of psychions, informational content of the superverse/multiverses, which becomes individuated consciousness recursively organized and reproduced as practical consciousness), which produces an EM field that holds together and integrates the qualia of the psychions as individuated consciousness. For Mocombe, building on BBBHT, the superverses with entangled and superimposed (via black holes) multiverses share the same informational content. So, the hypothesis here is that one superverse created a universe, and its informational content is entangled and superimposed on top of another superverse with the informational content of the previous universe emerging in it via black holes. Hence what you have are a layer of multiverses and superverses, superimposed and entangled, whose informational contents are shared or recycled via black holes, which organize and structure the multiverses similarly. As such, quantum fluctuation and big bangs are constantly occurring and producing the same worlds, ad infinitum. The informational content, qualia, of these multiverses and worlds are encoded and transmitted as psychions and embodied in the microtubules of neurons of brains, which create an EM field that holds and integrates the psychions as individuated consciousness.

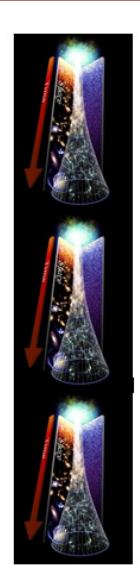

Figure 2: For Mocombe, building on BBBHT, the superverses with entangled and superimposed (via black holes) multiverses share the same informational content. So, the hypothesis here is that one superverse created a universe, and its informational content is entangled and superimposed on top of another superverse with the informational content of the previous universe emerging in it via black holes. Hence what you have are a layer of multiverses and superverses, superimposed and entangled, whose informational content are shared or recycled via black holes, which organize and structure the multiverses similarly. As such, quantum fluctuation and big bangs are constantly occurring and producing the same worlds, ad infinitum. So, when physicists look out to the cosmic microwave background (CMB), they are looking at the remnant from an early stage of our universe, which came forth from its older version a layer above it, and so on ad infinitum. Put more concretely, the physicists are in a superverse, of our universe, in our milky-way galaxy, looking out to the black hole of a milky-way galaxy from the superverse/multiverse above us. 


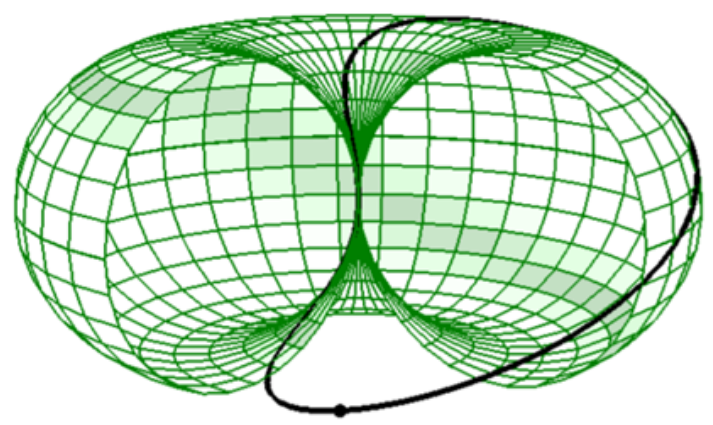

Figure 3: The union model composed of a superluminal primordial information quantum (spring). The mathematical horn torus surface on which the spring travels is cut away to show the interior. The black closed curve on the surface of the torus is the trajectory of the unions spring (indicated by the black dot).

For Mocombe, building on BBBHT, the superverses with entangled and superimposed (via black holes) multiverses share the same informational content. So, the hypothesis here is that one superverse created a universe, and its informational content is entangled and superimposed on top of another superverse with the informational content of the previous universe emerging in it via black holes. Hence what you have are a layer of multiverses and superverses, superimposed and entangled, whose informational content are shared or recycled via black holes, which organize and structure the multiverses similarly. As such, quantum fluctuation and big bangs are constantly occurring and producing the same worlds, ad infinitum. So, when physicists look out to the cosmic microwave background ( $\mathrm{CMB}$ ), they are looking at the remnant from an early stage of our universe, which came forth from its older version a layer above it, and so on ad infinitum. Put more concretely, the physicists are in a superverse, of our universe, in our milky-way galaxy, looking out to the black hole of a milky-way galaxy from the superverse/multiverse above us.

Figure 4. This figure represents how the psychions are embodied from the consciousness field (CF) in the microtubules of neurons of brains (figure a, adopted from McFadden, 2020, represents the human brain-left (L) and right (R) hemispheresand its EM field, which holds together and integrates the qualia of psychions, informational content of the superverse/multiverses, which becomes individuated consciousness recursively organized and reproduced as practical consciousness), which produces an EM field that holds together and integrates the qualia of the psychions as individuated consciousness. For Mocombe, building on BBBHT, the superverses with entangled and superimposed (via black holes) multiverses share the same informational content. So, the hypothesis here is that one superverse created a universe, and its informational content is entangled and superimposed on top of another superverse with the informational content of the previous universe emerging in it via black holes. Hence what you have are a layer of multiverses and superverses, superimposed and entangled, whose informational contents are shared or recycled via black holes, which organize and structure the multiverses similarly. As such, quantum fluctuation and big bangs are constantly occurring and producing the same worlds, ad infinitum. The informational content, qualia, of these multiverses and worlds are encoded and transmitted as psychions and embodied in the microtubules of neurons of brains, which create an EM field that holds and integrates the psychions as individuated consciousness.

$$
\begin{gathered}
x(t)=R(1+\cos (\omega t)) \cos (\omega t) \\
y(t)=R(1+\cos (\omega t)) \sin (\omega t) \\
z(t)=R \sin (\omega t) \\
R=\hbar / M c=2.9 \times 10^{-97} \mathrm{~m} \\
\omega=M c^{2} / \hbar=1.0 \times 10^{105} \text { radians } / \mathrm{s} \\
M=\text { mass of observable universe }=1.2 \times 10^{54} \mathrm{~kg}
\end{gathered}
$$

Figure 4: The parametric equations of the univon of the model composed of a circulating spring. The calucalted maxmium speed of the circulating spring is $c=2.236 \mathrm{c}$ (at the equtor of the mathematical torus) while its minimum speed is $\mathrm{c}$ (at the centre of the mathematical tours). 


\section{Acknowledgment}

None.

\section{Conflict of Interest}

No conflict of interest.

\section{References}

1. McFadden Johnjoe (2020) Integrating Information in the Brain's EM Field: the cemi Field Theory of Consciousness", Neurosci Conscious 2020(1): niaa016.

2. Mocombe Paul C (2016) The Vodou Ethic and the Spirit of Communism: The Practical Consciousness of the African People of Haiti. Maryland: University Press of America.

3. Mocombe Paul C (2017) The Soul-less Souls of Black Folk: A Sociological Reconsideration of Black Consciousness as Du Boisian Double Consciousness. Maryland: University Press of America.

4. Mocombe Paul C (2018) The Theory of Phenomenological Structuralism. United Kingdom: Cambridge Scholars Publishing.

5. Hameroff, Stuart and Roger Penrose (2014) "Consciousness in the Universe: A Review of the 'Orch or' theory." Physics of Life Reviews 11(1): 39-78.

6. Gauthier Richard (2020) Big Bangs Created by Univon Particles from a Conscious Quantum Field-Towards the Next Scientific Revolution.

7. Anderson Tim (2020) The Big Bang may be a Black Hole Inside Another Universe, retrieved from www.medium.com, accessed 27 July 2020.

8. Crothers Charles (2003) Technical Advances in General Sociological Theory: The Potential Contribution of Post-Structurationist Sociology." Perspectives 26: 3-6.

9. Ortner Sherry (1984) Theory in Anthropology Since the Sixties, Comparative Studies in Society and History 26: 126-66.

10. Althusser Louis (2001) Lenin and Philosophy and Other Essays. New York: Monthly Review Press.

11. Althusser Louis, Étienne Balibar (1970) Reading Capital (Ben Brewster Trans.). London: NLB.

12. Balibar Etienne, Immanuel Wallerstein (1991[1988]) Race, Nation, Class: Ambiguous Identities. London: Verso.

13. Buck Morss Susan (2009) Hegel, Haiti, and Universal History. Pittsburgh: University of Pittsburgh Press.

14. Cohen J (2002) Protestantism and Capitalism: The Mechanisms of Influence. New York: Aldine de Gruyter.

15. Dahrendorf Ralf (1959) Class and Class Conflict in Industrial Society. Stanford, California: Stanford University Press.

16. Douglas M (1986) How Institutions Think. New York: Syracuse University Press.

17. Fraser Nancy (1997) Justice Interruptus: Critical Reflections on the "Postsocialist" Condition. New York \& London: Routledge.

18. Holloway Joseph E (1990a) Africanisms in American Culture. Bloomington and Indianapolis: Indiana University Press.

19. Holloway Joseph E (1990b) The Origins of African American Culture. In Joseph Holloway (Ed.), Africanisms in American Culture Bloomington and Indianapolis: Indiana University Press. Pp. 19-33.
20. Horkheimer Max, Theodor W Adorno (2000) Dialectic of Enlightenment (John Cumming, Trans.). New York: Continuum.

21. Hudson Kenneth, Andrea Coukos (2005) The Dark Side of the Protestant Ethic: A Comparative Analysis of Welfare Reform. Sociological Theory 23 (1): 1-24.

22. James CLR (1986) The Black Jacobins: Toussaint L' Ouverture and the San Domingo Revolution.

23. Karenga Maulana (1993) Introduction to Black Studies. California: The University of Sankore Press.

24. Kellner Douglas (2002) Theorizing Globalization. Sociological Theory 20: 285-305.

25. Kurtz Lester R (2007) Gods in the Global Village: The World's Religions in Sociological Perspective. California: Sage Publications.

26. Lukács Georg (1971) History and Class Consciousness: Studies in Marxist Dialectics (Rodney Livingstone, Trans.). Cambridge, Massachusetts: The MIT Press.

27. Lukács Georg (2000) A Defence of History and Class Consciousness: Tailism and the Dialectic (Esther Leslie, Trans.). London and New York: Verso.

28. Marcuse Herbert (1964) One-Dimensional Man. Boston: Beacon Press.

29. Marcuse, Herbert (1974) Eros and Civilization: A Philosophical Inquiry into Freud. Boston: Beacon Press.

30. Marx Karl, Friedrich Engels (1964) The Communist Manifesto. London, England: Penguin Books.

31. Marx Karl (1992[1867]) Capital: A Critique of Political Economy (Volume 1, Samuel Moore and Edward Aveling, Trans.). New York: International Publishers.

32. Marx Karl (1998[1845]) The German Ideology. New York: Prometheus Books.

33. Patterson Orlando (1982) Slavery and Social Death: A Comparative Study. Cambridge, Massachusetts: Harvard University Press.

34. Ramsey Kate (2011) The Spirits and the Law: Vodou and Power in Haiti. Chicago: University of Chicago Press.

35. Rubin, Vera (1960) Caribbean Studies: A Symposium. Seattle: University of Washington Press.

36. Sklair Leslie (1995) Sociology of the Global System. Baltimore: Westview Press.

37. Smith MG (1960) The African Heritage in the Caribbean. In Vera Rubin (Ed.), Caribbean Studies: A Symposium Seattle: University of Washington Press. pp. 34-46.

38. Wallerstein Immanuel (1982) The Rise and Future Demise of the World Capitalist System: Concepts for Comparative Analysis. In Hamza Alavi and Teodor Shanin (Eds.), Introduction to the Sociology of "Developing Societies" New York: Monthly Review Press. pp. 29-53.

39. Weber Max (1958 [1904-1905]) The Protestant Ethic and the Spirit of Capitalism (Talcott Parsons, Trans.). New York: Charles Scribner's Sons. 